\title{
Invited Articles Foreword
}

The Invited Articles section of this issue consists of two articles. The article "Uniform, Integral, and Feasible Proofs for the Determinant Identities," by Iddo Tzameret and Stephen Cook, was invited from the 32nd ACM/ IEEE Symposium on Logic in Computer Science (LICS'17). We want to thank the LICS'17 Program Committee for their help in selecting this invited article, and editor Andrew Pitts for handling the article. The second article, "Exploiting Spontaneous Transmissions for Broadcasting and Leader Election in Radio Networks," by Artur Czumaj and Peter Davies, won the best student paper award at the 36th ACM Symposium on Principles of Distributed Computing (POCD'17). We want to thank the PODC'17 Program Committee for their help in selecting this invited article, and editor Christian Scheideler for handling the article.

Eva Tardos

Editor-in-Chief

\section{ACM Reference format:}

Eva Tardos. 2021. Invited Articles Foreword. J. ACM 68, 2, Article 12e (March 2021), 1 page. https://doi.org/10.1145/3456290

(C) 2021 Copyright held by the owner/author(s).

0004-5411/2021/03-ART12e

https://doi.org/10.1145/3456290 